\title{
Synthesis of oligosaccharides of biological importance
}

\author{
Per J. Garegg, Peter Konradsson, Daina Lezdins, Stefan Oscarson, Katinka \\ Ruda and Liselotte Öhberg \\ Department of Organic Chemistry, Arrhenius Laboratory, Stockholm \\ University, S-106 91 Stockholm, Sweden
}

\begin{abstract}
Syntheses of a variant of myo-inositol-containing compounds are discussed and described, including glycan phosphatidylinositol structures found on various cell surfaces and believed to play important roles in the life cycles of tropical parasites (Trypanosoma and Leishmania) and in the action of insulin, and phosphatidyl inositol phosphates, known signal substances in a number of biological events. The resolution of myo-inositol is performed using camphor acetals and the phosphodiester linkages are introduced using $\mathrm{H}$-phosphonates.
\end{abstract}

myo-Inositol appears widely in Nature, most frequently as phosphorylated or phospholipid derivatives, but $O$-methyl and glycosyl inositols have also been identified and synthesized (ref. 1 and 2). The discovery that inositol derivatives containing phosphates, phospholipids, glycans or glycan bound proteins are involved or act as "second messengers" in various cell regulation systems, has dramatically increased the interests in these compounds (ref. 3 and 4). Most eukaryotic cells utilize glycosyl phosphatidylinositols (GPIs) to anchor proteins to the cell membrane. Partial structural data, accumulated for over 100 GPI membrane-anchored proteins from a variety of organisms, have led to the proposal of the generalized anchor structure depicted in Fig. 1.

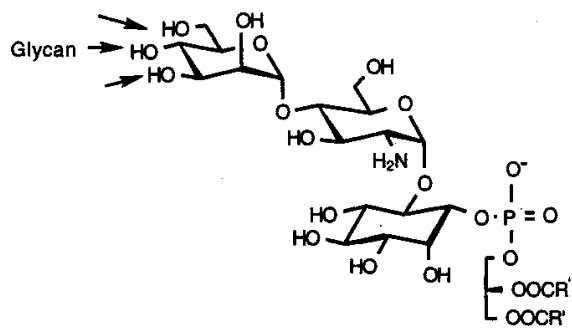

Figure 1. Common structure for the phosphatidyl anchoring system.

Only three of these structures have thus far been fully characterized, the variant surface glycoprotein (VSG) from Trypanosoma (ref. 5) and Leishmania (ref. 6) (Fig. 2), and the Thy1 glycoprotein anchor from rat brain (ref. 7). We are now synthesizing parts of the Leishmania structure. Parts of the structures of Trypanosoma (ref. 8), Leishmania (ref.9) and the Thy-1 glycoprotein anchor (ref. 10), have already been synthesized by others. 


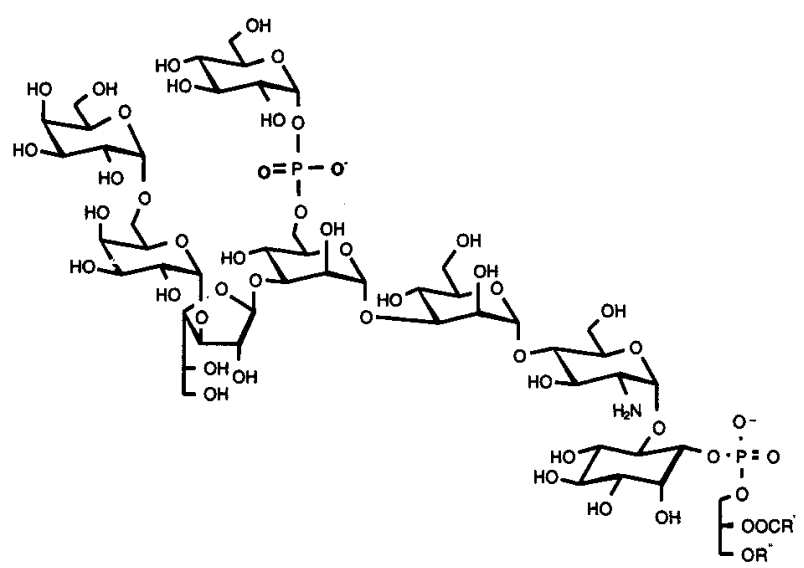

Figure 2. Part of the structure found in Leishmania.

In our early work, racemic dicyclohexylidene derivatives of myo-inositol were resolved into enantiomers via derivatization with optically active agents, e.g. in our laboratory mono-Ltartrates (ref. 1) and mandelic acid esters (ref. 2). In more recent work (ref. 11), derivatization of myo-inositol with D-camphor has provided a convenient and elegant resolution giving 2,3substituted 1D-myo-inositol.

A phospho-oligosacharide has been proposed as a "second messenger" of insulin (ref. 12). It is believed to be structurally related to the glycolipid part of the glycosyl-phosphatidylinositol anchors. The biologically active inositol phosphoglycan (IPG) is generated by a specific phospholipase. The structure of this IPG has not been determined, but evidence indicates the presence of myo-inositol glycosidically linked to a non-acetylated glucosamine unit, which itself is coupled to an oligosaccharide (Fig. 3). Biological results have indicated that it is probably the cyclic phosphate (compound $\underline{2}$, Fig. 3 ) that mediates the action of insulin (ref. 13a). IPG structures are also known to be generated in response to growth factors.

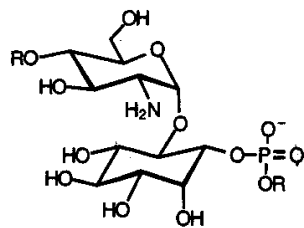

1a $R=$ Glycan 1b $\mathrm{R}=\mathrm{H}$

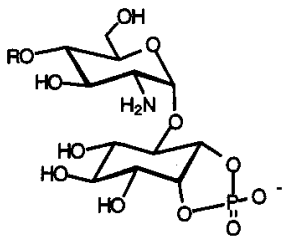

2a $R=$ Glycan $2 \mathrm{~b} R=\mathrm{H}$

Figure 3

The structures depicted in Fig. 3 and analogues thereof have now been synthesized in a short and efficient way. These structures have also been synthesized by other groups (ref. 13). Starting from the easily obtainable compound $\underline{3}$ (ref. 14), glycosyl donor 4 can, by standard procedure, be synthesized in five steps (Scheme 1). From the protocol of Bruzik et al. (ref. 11) myo-inositol derivative $\underline{5}$ was achieved in two steps. Glycosylation of $\underline{4}$ with $\underline{5}$ gave the protected compound $\underline{6}$ in moderate yield. Several other glycosylation methods were tried, but gave many byproducts and lower yields. 


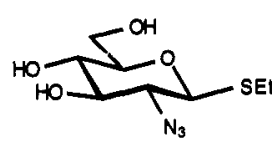

$\underline{3}$

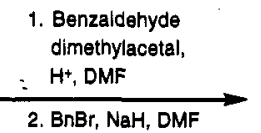

$(87 \%)$
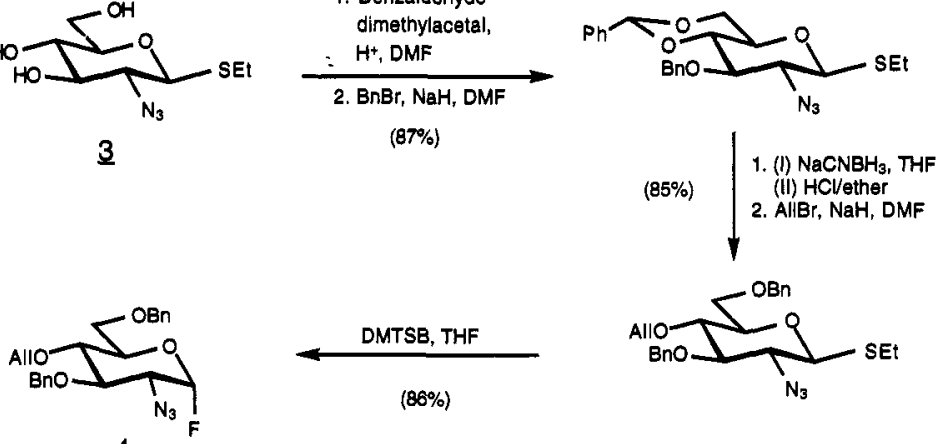

4

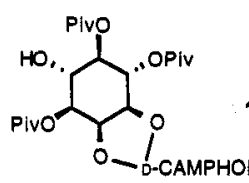

$\mathrm{AgOTf}, \mathrm{Cp}_{2} \mathrm{ZrCl}_{2}$

$(48 \%)$

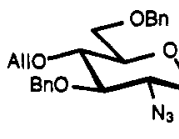

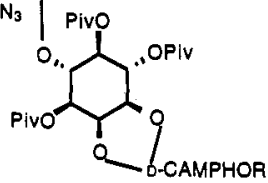

6

Scheme 1

Protecting group manipulation, phosphorylation, and deprotection of compound 6 according to Scheme 2 gave the acyclic target compound $\underline{1 b}$. The allyl group in derivative $\mathbf{Z}$, may selectively be removed under neutral conditions to allow further glycosylation. Ring closure of the monophosphate using a carbodiimide derivative (ref. 13a) afforded the cyclic phosphate $\underline{2 b}$.

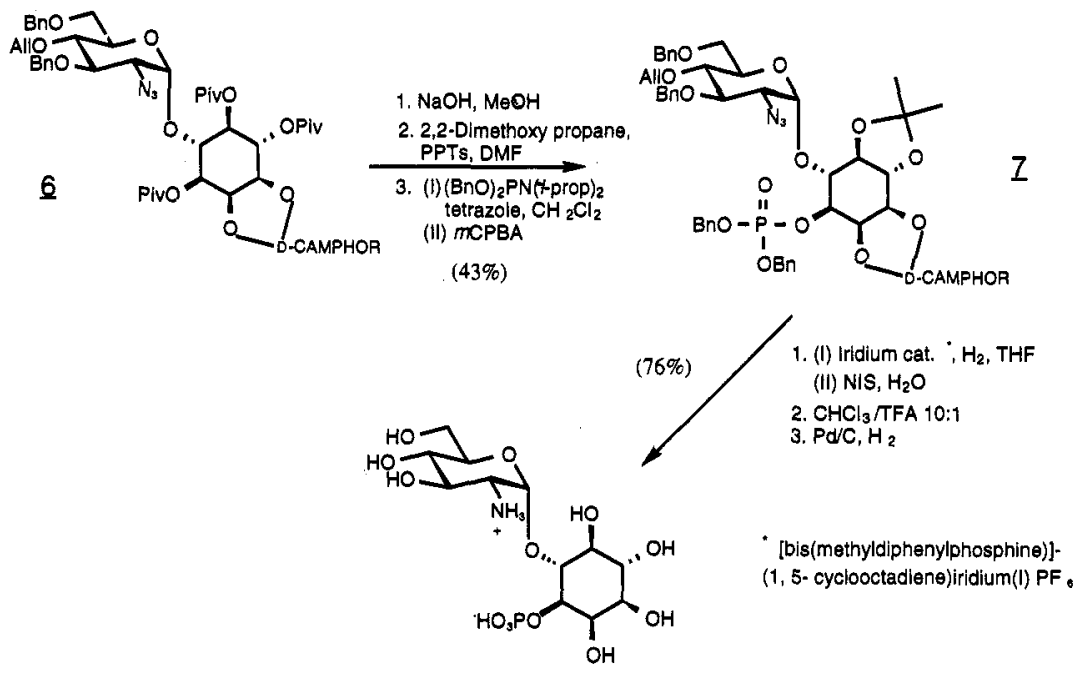

Scheme 2 
Inositol-(4,5)-diphosphate is a well-known precursor for a $\mathrm{Ca}^{2+}$-mobilized "second messenger" inositol-(1,4,5)-triphosphate $\left(\mathrm{IP}_{3}\right)$. The metabolism and biological function of $\mathrm{IP}_{3}$ have been described in detail during the last decade (ref. 3 and 4 ). More recently a phosphatidyl-inositol-(3,4,5)-triphosphate $\left(\mathrm{PIP}_{3}\right)$ has been found (ref. 15). $\mathrm{PIP}_{3}$ (Fig. 4) is believed to initiate actin polymerisation in neutrophiles, respiratory burst, protein synthesis, secretion and glucose metabolism. PIP $_{3}$ has been synthesized by other groups (ref. 16 and 17).

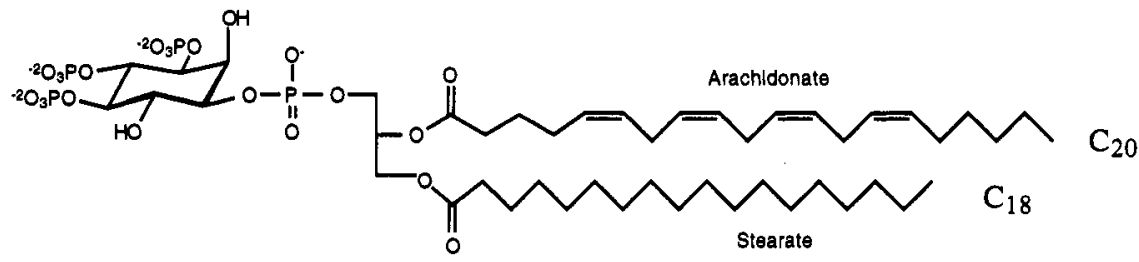

Figure 4 The structure of phosphatidyl-inositol-(3,4,5)-triphosphate $\left(\mathrm{PIP}_{3}\right)$

Starting from compound 8 , derivative 9 was synthesized in eight steps with an overall yield of $40 \%$ (Scheme 3 ). The synthetic scheme follows, with a few exceptions, earlier published work (ref. 16).

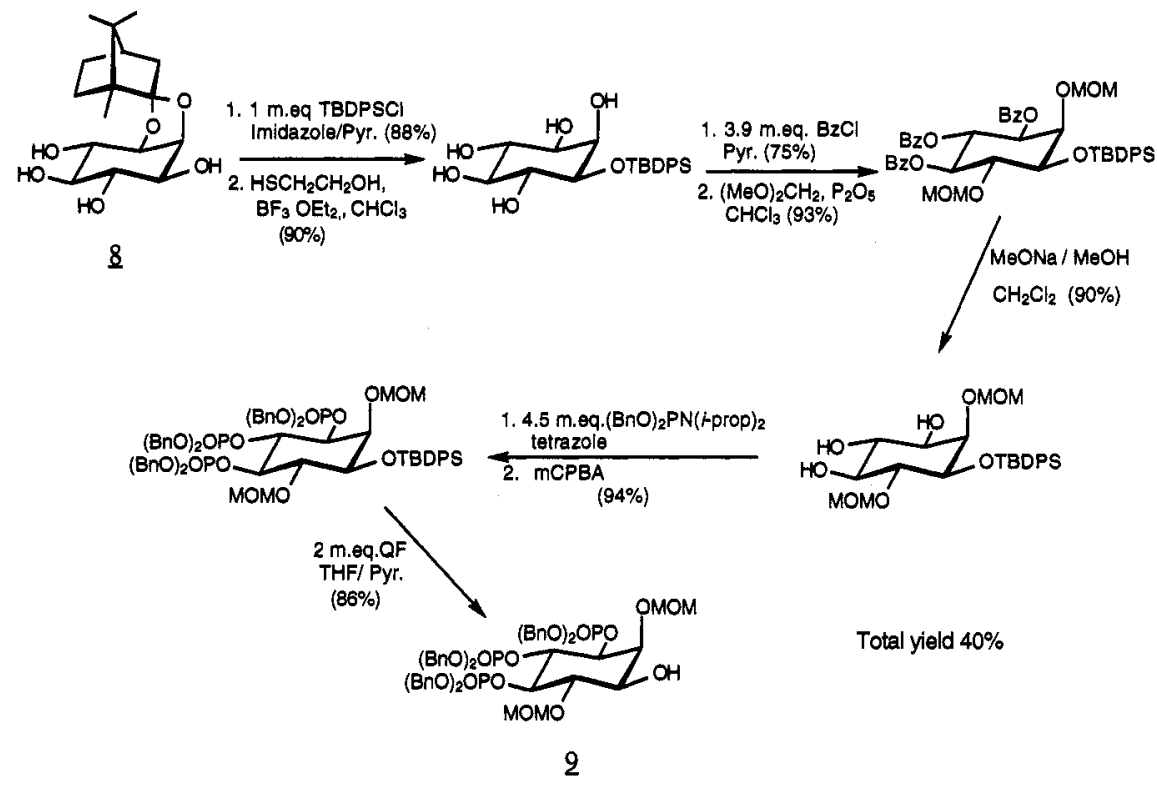

Scheme 3

The di-acylglycerol derivative 11 was synthesized, using known procedures, from the commercially available glycerol derivative 10 (Scheme 4). Under controlled conditions, monoacylation was achieved (compound 12). This compound will, after several synthetic steps, be used to connect arachidonic acid or a suitable spacer. A new method was used (ref. 18) to construct the $\mathrm{H}$-phosphonate $\underline{11}$. 


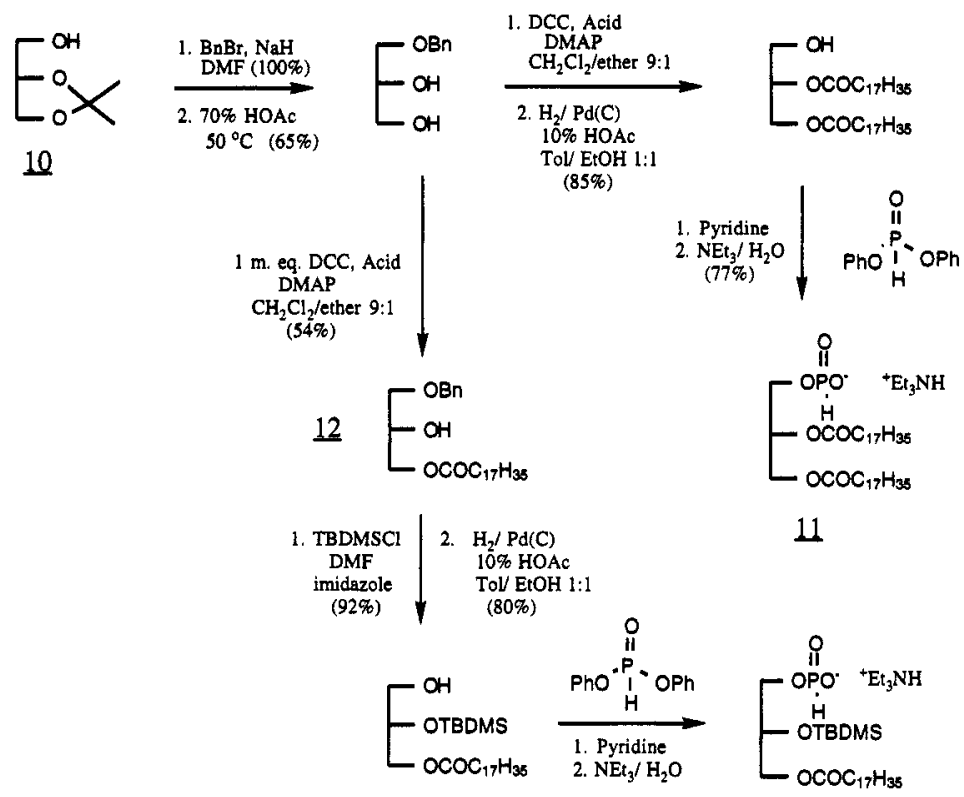

Scheme 4

The myo-inositol and glycerol derivatives 9 and 11 were connected by the $H$-phosphonate method, developed in our laboratories (ref. 19). By the use of this method, both the oxygen compound 13 and the sulfur analogue 14 could be synthesized. Deprotection to compound 15 using TMSBr, which will remove both the benzyl esters and MOM-ethers is still under investigation. Other published methods (ref. 16 and 17), involve at least a two step procedure.

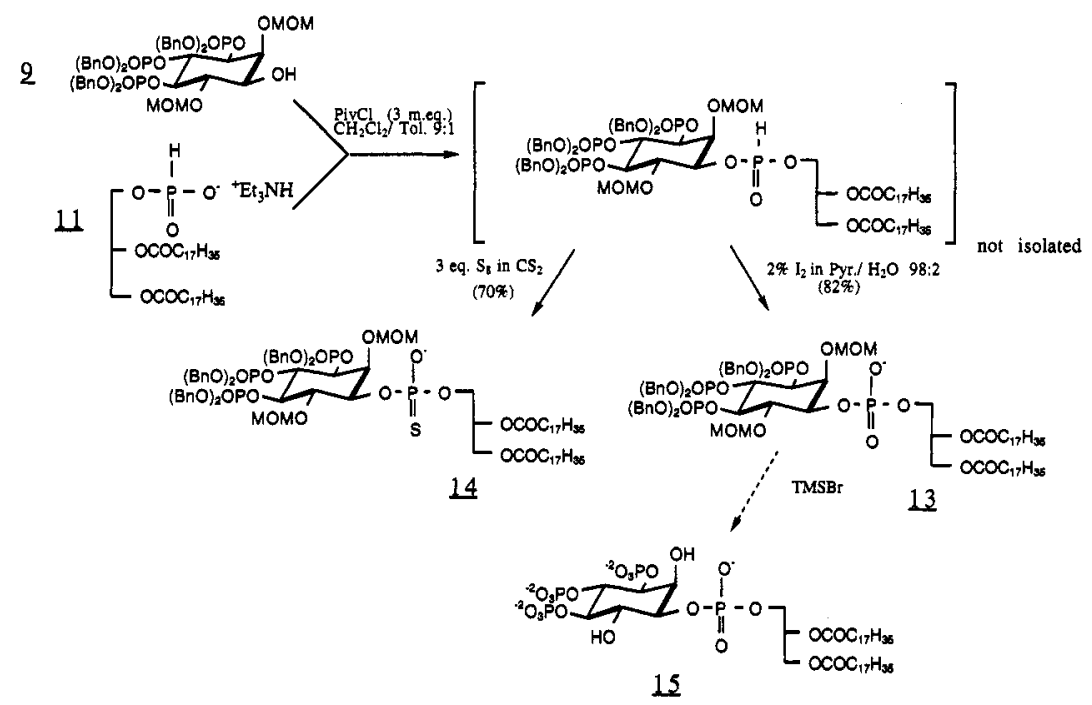

Scheme 5 


\section{References}

1. P. Konradsson Chem. Comm. Univ. of Stockholm, No. 5, (1987).

2. S. C. T. Svensson, Chem. Comm. Univ, of Stockholm, No. 2, (1987).

3. A. B. Reitz, Inositol Phosphates and Derivatives, ACS Symposium series 463, (1991) and references cited therein.

4. S. Potter and D. Lampe, Angew. Chem. Int. Ed., 34, 1933, (1995) and references cited therein.

5 M. A. J. Ferguson, M. G. Low and G. A. M. Cross, J. Biol. Chem., 260, 14547, (1985).

6. M. J. McConville and M. A. J. Ferguson, Biochem. J., 294, 305, (1993).

7. M. A. J. Ferguson, S. W. Homans, R. A. Dwek, and T. W. Rademacher, Science, 239, 753, (1988).

8. a) D. R Mootoo, P. Konradsson, and B. Fraser- Reid, J. Am. Chem. Soc., 111, 8540, (1989), b) G. R. Verduyn, J. J. A. Belien, C. M. Dreef-Tromp, G. A. van Marel, and J. H. van Boom, Tetrahedron Lett., 32, 6637, (1991), c) C. Murakata and T. Ogawa Carbohydr. Res., 235, 95, (1992), d) G.-J. Boons, P. Price, R. Leslie, S. V. Ley, and L. L. Yeung, Tetrahedron Lett., 34, 9525, (1993), e) S. Cottaz, J. S. Brimacombe, and M. A. J. Ferguson, J. Chem. Soc., Perkin Trans 1, 2949, (1993), f) R. Madsen, U. E. Udodong, C. Roberts, D. R. Mootoo, P. Konradsson, and B. Fraser-Reid, J. Am. Chem Soc. 117, 1554, (1995), g) J. Ye, W. T. Doerrler, M. A. Lehrman and J. R. Falck, Bioorg. Med. Chem. Lett., 6, 1715, (1996).

9. A. V. Nikolaev, T. J. Rutherford, M. A. J. Ferguson and J. S. Brimacombe, J. Chem. Soc., Perkin Trans., 1559, (1996).

10. S. Campbell and B. Fraser-Reid, J. Am. Chem. Soc, 117, 10387, (1995).

11. K. S. Bruzik and M-D. Tsai, J. Am. Chem. Soc., 114, 6361, (1992)

12. a) S. Alemany, J. M. Mato and P. Strålfors, Nature, 330, 77, (1987), b) P. Strålfors, Nature, 335, 554, (1988).

13. a) R. Plourde, M. d.Aarcao, and A. R. Saltiel, J. Org. Chem., 57, 2609, (1992), b) A. Zapata, Y. Leon, J. M. Mato, I. Varela-Nieto, S. Penades and M. Martin-Lomas, Carbohydr. Res., 264, 21, (1994).

14. T. Buskas, P. J. Garegg, P. Konradsson, and J.-L. Maloisel, Tetrahedron Asymmetry, 5, 2187, (1994).

15. L. R. Stephens, T. R. Jackson and P. T. Hawkins, Biochim. Biophys. Acta, 1179, 27, (1993), b) M. Baggiolini, and M. P. Wymann, Trends Biochem. Sci., 15 69, (1990), c) Stossel, T. P. 1993. Am. Scientist., 78 408, (1993).

16. K. S. Bruzik and R. J. Kubiak, Tetrahedron Lett., 36, 2415, (1995).

17. Y. Watanabe, M. Tomioko, and S. Ozaki, Tetrahedron, 33, 8969, (1995).

18. J. Jankowska, M. Sobkowski, J. Stawinski and A. Kraszewski, Tetrahedron Lett., 35, 3355, (1994).

19. J. Stawinsky, In Handbook of Organophosphorus Chemistry (R. Engel, ed), p 377 Marcel Dekker, New York (1992). 